\title{
Pesquisa de Rickettsia spp em carrapatos Amblyomma cajennense e Amblyomma dubitatum no Estado de São Paulo
}

\author{
Survey of Rickettsia spp in the ticks Amblyomma cajennense \\ and Amblyomma dubitatum in the State of São Paulo
}

\author{
Richard Campos Pacheco', Maurício Cláudio Hortaㄹ, Adriano Pinter ${ }^{2}$, Jonas Moraes-Filho', \\ Thiago Fernandes Martins ${ }^{1}$, Marcello Schiavo Nardi', \\ Savina Silvana Aparecida Lacerra de Souza², Celso Eduardo de Souza², \\ Matias Pablo Juan Szabó ${ }^{3}$, Leonardo José Richtzenhain ${ }^{1}$ e Marcelo Bahia Labruna ${ }^{1}$
}

\begin{abstract}
RESUMO
Foi pesquisada a presença de riquétsias em 3.545 carrapatos Amblyomma cajennense e 2.666 Amblyomma dubitatum. Através do teste de hemolinfa, reação em cadeia pela polimerase e isolamento de rickettsia em cultivo celular, todos os Amblyomma cajennense foram negativos, sendo que 634 (23,8\%) Amblyomma dubitatum mostraram-se infectados com Rickettsia bellii.
\end{abstract}

Palavras-chaves: Carrapatos. Amblyomma dubitatum. Amblyomma cajennense. Rickettsia bellii. Isolamento em cultivo celular.

\begin{abstract}
The presence of rickettsial infection was surveyed in 3,545 Amblyomma cajennense ticks and 2,666 Amblyomma dubitatum ticks. Using the hemolymph test, polymerase chain reaction and isolation of Rickettsia in cell cultures, all of the Amblyomma cajennense were negative, whereas 634 (23.8\%) of the Amblyomma dubitatum ticks were shown to be infected with Rickettsia bellii.
\end{abstract}

Key-words: Ticks. Amblyomma dubitatum. Amblyomma cajennense. Rickettsia bellii. Isolation in cell culture.

A febre maculosa brasileira (FMB), doença causada pela bactéria Rickettsia rickettsii, é o principal agravo em consequiência da infecção por riquétsias do grupo da febre maculosa (GFM) em humanos no Brasil. Casos confirmados de FMB têm sido relatados em determinadas áreas dos Estados da região Sudeste ${ }^{18}$. 0 carrapato Amblyomma cajennense é incriminado como o principal vetor da doença ${ }^{5}$ e, embora não haja comprovação do papel do Amblyomma dubitatum na transmissão da FMB, suspeita-se de sua possível participação na transmissão de riquétsias do GFM para humanos ${ }^{112}$. Os eqüinos, capivaras e antas estão entre os principais hospedeiros para todos os estágios parasitários de Amblyomma cajennense ${ }^{7}$, enquanto as capivaras são também hospedeiros primários para o Amblyomma dubitatum $^{9}$. Desta forma, este trabalho buscou avaliar a infecção

\footnotetext{
1. Departamento de Medicina Veterinária Preventiva e Saúde Animal, Faculdade de Medicina Veterinária e Zootecnia, Universidade de São Paulo, São Paulo, SP. 2. Superintendência de Controle de Endemias, São Paulo, SP. 3. Faculdade de Medicina Veterinária, Universidade Federal de Uberlândia, Uberlândia, MG. Apoio financeiro: FAPESP (processo n. ${ }^{\circ}$ 03/13871-8)

Endereço para correspondência: Dr. Richard de Campos Pacheco. Laboratório de Doenças Parasitárias/Depto. Med. Vet. Preventiva e Saúde Animal/FMVZ/USP. Av. Prof. Dr. Orlando Marques de Paiva 87, Cidade Universitária, 05508-270 São Paulo, SP. Tel: 5511 3091-1394; Fax: 5511 3091-7928

e-mail: pachecorc@hotmail.com

Recebido para publicação em 25/06/2008

Aceito em 29/04/2009
}

por Rickettsia spp em carrapatos Amblyomma cajennense e Amblyomma dubitatum no Estado de São Paulo.

Durante o período de 2002 a 2006, carrapatos adultos das espécies Amblyomma cajennense e Amblyomma dubitatum, provenientes de 16 localidades do Estado de São Paulo (Figura 1), foram capturados em vida livre e, também através da retirada manual sobre as capivaras. Os carrapatos foram inicialmente submetidos ao teste de hemolinfa ${ }^{2}$, método de triagem para detectar organismos morfologicamente compatíveis com riquétsias e, em seguida congelados a $-80^{\circ} \mathrm{C}$ para posterior processamento. Os carrapatos positivos pelo teste de hemolinfa tiveram suas patas removidas, sem que o corpo fosse descongelado, as quais foram submetidas à extração de DNA e a técnica da reação em cadeia pela polimerase (PCR) utilizandose os oligonucleotídeos CS-78 e CS-323, que amplificam um fragmento de 401 pares de base $(\mathrm{pb})$ do gene citrato sintase ( $g l t A$ ), presente em todas as espécies de riquétsias ${ }^{11}$. Se positivo, a amostra de DNA era testada por outro PCR utilizando-se os oligonucleotídeos Rr190.70p e Rr190.602n, os quais amplificam um fragmento de 530pb do gene ompA (proteína de $190 \mathrm{kDa}$ ), presente apenas em riquétsias do $\mathrm{GFM}^{16}$. Produtos da PCR foram purificados e, em seguida o DNA de cada amostra foi sequienciado ${ }^{14}$. As sequiências obtidas foram submetidas ao programa BLAST analysis para determinar similaridades com outras espécies de riquétsias ${ }^{1}$. 


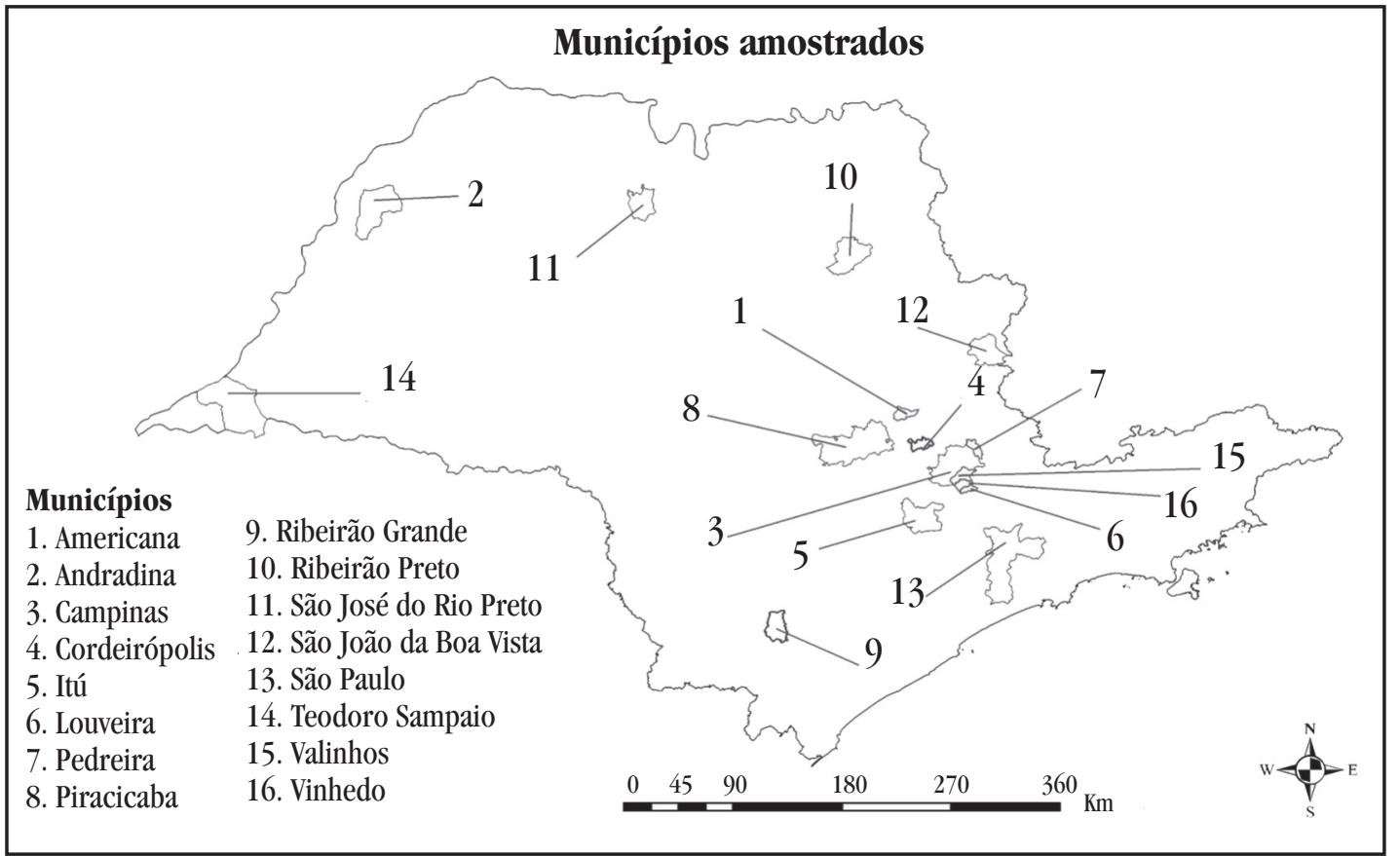

\section{FIGURA 1}

Localização dos 16 municípios no Estado de São Paulo, onde foram coletados as amostras de carrapatos Amblyomma cajennense e Amblyomma dubitatum, no período de 2002 a 2006.

Dois carrapatos Amblyomma dubitatum, positivos na PCR para o gene gltA, foram descongelados e submetidos à técnica de isolamento de riquétsias em cultura de células Vero, conforme previamente descrito ${ }^{11}$. Depois de estabelecido os isolados, foi realizado a extração de DNA de uma alíquota de cada inoculo, a qual foi testada por uma bateria de PCR's, objetivando a caracterização molecular dos isolados. Para a realização de cada reação foram utilizados os oligonucleotídeos CS-239 e CS-1069, que amplificam um fragmento de $834 \mathrm{pb}$ do gene glt $A^{11}$, oligonucleotídeos $17 \mathrm{k}-5$ e $17 \mathrm{k}-3$, os quais amplificam um fragmento de $549 \mathrm{pb}$ do gene htrA (proteína de $17 \mathrm{kDa})^{11}$, oligonucleotídeos 120-M59 e 120-807 para amplificação de uma fragmento de $865 \mathrm{pb}$ do gene ompB (proteína de $135 \mathrm{kDa}$ ) ${ }^{17}$ e, por fim uma alíquota dos isolados foi testada pela PCR utilizando os oligonucleotídeos Rr190.70p e $\operatorname{Rr} 190.602 \mathrm{n}^{16}$.

Um total de 3.545 carrapatos Amblyomma cajennense e 2.666 Amblyomma dubitatum foi coletado nas 16 áreas estudadas. Dos Amblyomma cajennense, 3.517 foram negativos pelo teste de hemolinfa e 28 amostras foram inconclusivas, em conseqüência de problemas inerentes à técnica. Dos 2.666 Amblyomma dubitatum, 2.019 foram negativos no teste de hemolinfa, 244 foram inconclusivos e em 403 amostras foi possível observar organismos morfologicamente compatíveis com riquétsias.

Os 28 carrapatos Amblyomma cajennense inconclusivos pelo teste de hemolinfa foram negativos pela PCR. Dos 647 Amblyomma dubitatum positivos e inconclusivos, 634 (403 previamente positivos e 231 inconclusivos no teste de hemolinfa) foram positivos na PCR para o gene gltA (Tabela 1). Nenhum deles foi positivo para o gene ompA. Os produtos da PCR dos 634 Amblyomma dubitatum positivos nessa técnica foram seqüenciados e todas as sequiências obtidas mostraram 100\% de

\section{TABELA 1}

Número total de carrapatos Amblyomma cajennense e Amblyomma dubitatum coletadas por localidade durante o período de 2002 a 2006 em 16 municípios do Estado de São Paulo e frequiência de carrapatos positivos para Rickettsia bellii pela PCR.

\begin{tabular}{|c|c|c|c|c|c|c|}
\hline \multirow{3}{*}{$\begin{array}{l}\text { Localidade } \\
\text { (Município) }\end{array}$} & \multicolumn{3}{|c|}{ Amblyomma cajennense } & \multicolumn{3}{|c|}{ Amblyomma dubitatum } \\
\hline & \multirow{2}{*}{$\frac{\text { coletado }}{n^{0}}$} & \multicolumn{2}{|c|}{ positivo na PCR } & \multirow{2}{*}{$\frac{\text { coletado }}{n^{0}}$} & \multicolumn{2}{|c|}{ positivo na PCR } \\
\hline & & $\mathrm{n}^{\mathrm{o}}$ & $\%$ & & $\mathrm{n}^{\mathrm{o}}$ & $\%$ \\
\hline Americana & 7 & 0 & 0,0 & 15 & 1 & 6,7 \\
\hline Andradina & 10 & 0 & 0,0 & 26 & 0 & 0,0 \\
\hline Campinas & 135 & 0 & 0,0 & 186 & 35 & 18,8 \\
\hline Cordeirópolis & 6 & 0 & 0,0 & 432 & 69 & 15,9 \\
\hline Itu & 88 & 0 & 0,0 & 196 & 46 & 23,4 \\
\hline Louveira & 3 & 0 & 0,0 & 94 & 23 & 24,4 \\
\hline Pedreira & 555 & 0 & 0,0 & 841 & 378 & 44,9 \\
\hline Piracicaba & 2.662 & 0 & 0,0 & 499 & 52 & 10,4 \\
\hline Ribeirão Grande & 10 & 0 & 0,0 & 210 & 13 & 6,1 \\
\hline Ribeirão Preto & 39 & 0 & 0,0 & 13 & 0 & 0,0 \\
\hline São José do Rio Preto & 0 & 0 & 0,0 & 10 & 0 & 0,0 \\
\hline São João da Boa Vista & 4 & 0 & 0,0 & 0 & 0 & 0,0 \\
\hline São Paulo & 21 & 0 & 0,0 & 106 & 12 & 11,3 \\
\hline Teodoro Sampaio & 0 & 0 & 0,0 & 14 & 0 & 0,0 \\
\hline Valinhos & 2 & 0 & 0,0 & 24 & 5 & 20,8 \\
\hline Vinhedo & 3 & 0 & 0,0 & 0 & 0 & 0,0 \\
\hline Total & 3.545 & 0 & 0,0 & 2.666 & 634 & 23,8 \\
\hline
\end{tabular}

PCR: reação em cadeia da polimerase.

similaridade com as seqüências correspondentes de Rickettsia bellii disponíveis no GenBank (números de acesso CP000087, DQ865204, DQ517288 e U59716). Dos 16 municípios amostrados, 10 apresentaram carrapatos Amblyomma dubitatum infectados por Rickettsia bellii, numa frequiência geral de $23,8 \%$, variando 
de 6,1 a 44,9\% por população de carrapato infectada (Tabela 1). Foram obtidos dois isolados de Rickettsia bellii, provenientes de dois carrapatos Amblyomma dubitatum dos municípios de Cordeirópolis e Ribeirão Grande e, designados como Ad-CORDSP e Ad-25-INT, respectivamente. Amostras de DNA de células infectadas da terceira passagem dos dois isolados geraram fragmentos de 1.078 a $1.092 \mathrm{pb}$ para o gene gltA e de 498 a $499 \mathrm{pb}$ para o gene $h t r A$, respectivamente, os quais mostraram todos $100 \%$ de identidade com seqüências correspondentes de Rickettsia bellii no GenBank (números de acesso CP000087 e CP000849 para Ad-CORD-SP; DQ865204 e AY362702 para Ad-25-INT). Fragmentos dos genes ompA e ompB não foram obtidos para esses dois isolados.

Embora o carrapato Amblyomma cajennense seja o principal vetor de Rickettsia rickettsii no Brasil'5, no presente estudo não foi possível verificar a infecção por nenhuma espécie de riquétsia neste carrapato. Sangioni e cols ${ }^{18}$ observaram resultado semelhante em seis outras áreas do Estado de São Paulo, possivelmente em consequiência de uma baixa infecção pela bactéria. Notavelmente, Labruna e cols ${ }^{8}$ observaram que 0 Amblyomma cajennense é parcialmente refratário à infecção por Rickettsia rickettsii, quando comparado com outras espécies de carrapatos. A Rickettsia bellii foi a única espécie de riquétsia encontrada infectando carrapatos Amblyomma dubitatum. Esta espécie de riquétsia, embora de patogenicidade desconhecida para os seres humanos, tem sido relatada infectando inúmeras espécies de carrapatos no Brasil, incluindo Amblyomma dubitatum, com frequiências variadas de 0 a $100 \%$, dependendo da espécie e população de carrapato ${ }^{4610111415}$.

Pacheco e cols ${ }^{13}$, avaliando a infecção por Rickettsia spp pela reação de imunofluorescência indireta (RIFI) em capivaras de seis municípios do Estado de São Paulo, onde nunca houve relatos de FMB em seres humanos, observaram evidências sorológicas de infecção por Rickettsia parkeri em capivaras de apenas um município e, por Rickettsia bellii em outros quatro locais, onde a maior parte das capivaras estavam infestadas por Amblyomma dubitatum. Esses resultados, em conjunto com o presente trabalho, indicam que enquanto a maior parte das populações de Amblyomma dubitatum do Estado de São Paulo encontramse infectada por Rickettsia bellii, a infecção por riquétsias do GFM, como a Rickettsia parkeri, parece ser um achado bem raro nessa espécie de carrapato ${ }^{11}{ }^{12}$. Futuros estudos deverão avaliar o papel da infecção por Rickettsia bellii em diferentes populações de carrapatos, especialmente no que diz respeito à ecologia de riquétsias do GFM, uma vez que é sabido que um carrapato infectado por uma espécie de Rickettsia se torna refratário à infecção por uma segunda espécie de Rickettsia ${ }^{3}$.

\section{AGRADECIMENTOS}

Agradecemos à Fundação de Amparo a Pesquisa do Estado de São Paulo pelo apoio financeiro e ao Cássio Peterka do Instituto de Pesquisa Ecológica pela colaboração na coleta de amostras de carrapato.

\section{REFERÊNCIAS}

1. Altschul SF, Gish W, Miller W, Myers EW, Lipman DJ. Basic local alignment search tool. Journal of Molecular Biology 215: 403-410, 1990.

2. Burgdorfer W. The hemolymph test. The American Journal of Tropical Medicine and Hygiene 19: 1010-1014, 1970.

3. Burgdorfer W, Hayes SF, Mavros AJ. Nonpathogenic rickettsiae in Dermacentor andersoni: a limiting factor for the distribution of Rickettsia rickettsii. In: Burgdorfer W, Anacker RL (eds) Rickettsiae and rickettsial diseases, Academic Press, Inc., New York, p. 585-594, 1981.

4. Estrada DA, Schumaker TTS, Souza CE, Rodrigues Neto EJ, Linhares AX. Detecção de riquétsias em carrapatos do gênero Amblyomma (Acari: Ixodidae) coletados em parque urbano do município de Campinas, SP. Revista da Sociedade Brasileira de Medicina Tropical 39: 68-71, 2006.

5. Guedes E, Leite RC, Prata MC, Pacheco RC, Walker DH, Labruna MB. Detection of Rickettsia rickettsii in the tick Amblyomma cajennense in a new Brazilian spotted fever-endemic area in the state of Minas Gerais. Memórias do Instituto Oswaldo Cruz 100: 841-845, 2005.

6. Horta MC, Labruna MB, Pinter A, Linardi PM, Schumaker TTS. Rickettsia infection in five areas of the state of São Paulo, Brazil. Memórias do Instituto Oswaldo Cruz 102: 793-801, 2007.

7. Labruna MB, Kerber CE, Ferreira F, Faccini JLH, Waal DT, Gennari SM. Risk factors to tick infestations and their occurrence on horses in the state of São Paulo, Brazil. Veterinary Parasitology 97: 1-14, 2001.

8. Labruna MB, Ogrzewalska M, Martins TF, Pinter A, Horta MC. Comparative susceptibility of larval stages of Amblyomma aureolatum, Amblyomma cajennense, and Rhipicephalus sanguineus to infection by Rickettsia rickettsii. Journal of Medical Entomology 45: 1156-1159, 2008.

9. Labruna MB, Pinter A, Teixeira RHF. Life-cycle of Amblyomma dubitatum (Acari: Ixodidae) using capybaras (Hydrochaeris hydrochaeris) as hosts. Experimental and Applied Acarology 32: 79-88, 2004.

10. Labruna MB, Whitworth T, Bouyer DH, McBride JW, Camargo LMA, Camargo EP, Popov V, Walker DH. Rickettsia bellii and Rickettsia amblyommii in Amblyomma ticks from the state of Rondônia, Western Amazon, Brazil. Journal of Medical Entomology 41: 1073-1081, 2004.

11. Labruna MB, Whitworth T, Horta MC, Bouyer DH, McBride JW, Pinter A, Popov V, Gennari SM, Walker DH. Rickettsia species infecting Amblyomma cooperi ticks from an area in the State of São Paulo, Brazil, where Brazilian spotted fever is endemic. Journal of Clinical Microbiology 42: 90-98, 2004.

12. Lemos ERS, Melles HHB, Colombo S, Machado RD, Coura JR, Guimarães MAA, Sanseverino SR, Moura A. Primary isolation of spotted fever in the group rickettsiae from Amblyomma cooperi collected from Hydrochaeris hydrochaeris in Brazil. Memórias do Instituto Oswaldo Cruz 91: 273-275, 1996.

13. Pacheco RC, Horta MC, Moraes-Filho J, Ataliba AA, Pinter A, Labruna MB. Rickettsial infection in capybaras (Hydrochoerus hydrochaeris) from São Paulo, Brazil: serological evidence for infection by Rickettsia bellii and Rickettsia parkeri. Biomédica 27: 364-371, 2007.

14. Pacheco RC, Rosa S, Richtzenhain L, Szabó MPJ, Labruna MB. Isolation of Rickettsia bellii from Amblyomma ovale and Amblyomma incisum ticks from Southern Brazil. Revista MVZ Córdoba 13: 1273-1279, 2008.

15. Pinter A, Labruna MB. Isolation of Rickettsia rickettsii and Rickettsia bellii in cell culture from the tick Amblyomma aureolatum in Brazil. Annals of New York Academic Science 1078: 523-529, 2006.

16. Regnery RL, Spruill CL, Plikaytis BD. Genotypic identification of rickettsiae and estimation of intraspecies sequence divergence for portions of two rickettsial genes. Journal of Bacteriology 173: 1576-1589, 1991.

17. Roux V, Raoult D. Phylogenetic analysis of members of the genus Rickettsia using the gene encoding the outer membrane protein rOmpB (ompB). International Journal of Systematic Evolution and Microbiology 50: 1449-1455, 2000 .

18. Sangioni LA, Horta MC, Vianna MCV, Gennari SM, Soares RM, Galvão MAM, Schumaker TTS, Ferreira F, Vidotto 0, Labruna MB. Rickettsial infection in animals and Brazilian Spotted Fever endemicity. Emerging Infectious Diseases 11: 265-269, 2005. 